\title{
Ferroptosis is associated with oxygen-glucose deprivation/reoxygenation-induced Sertoli cell death
}

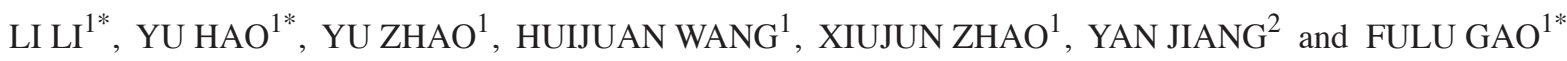 \\ ${ }^{1}$ Department of Histology and Embryology, Hebei Medical University, Shijiazhuang, Hebei 050017; \\ ${ }^{2}$ Reproductive Center, Shijiazhuang No. 4 Hospital, Shijiazhuang, Hebei 050019, P.R. China
}

Received July 31, 2017; Accepted February 2, 2018

DOI: 10.3892/ijmm.2018.3469

\begin{abstract}
Sertoli cell death contributes to spermatogenesis impairment, which is associated with male infertility. Testicular ischemia-reperfusion (I/R) injury induces the cell death of germ cells and Sertoli cells, whereas inhibition of cell death ameliorates acute testicular I/R damage. The aim of the present study was to investigate the mechanism of I/R stress-induced cell death in TM4 cells. Oxygen-glucose deprivation and reoxygenation (OGD/R) was demonstrated to induce I/R injury and cell death in TM4 cells. Cell death was blocked by the reactive oxygen species (ROS) inhibitor $\mathrm{N}$-acetylcysteine, as well as lipid peroxidation inhibitors Liproxstatin-1 and iron chelator deferoxamine; however, inhibitors of apoptosis, necrosis or autophagy had no effect. It was also demonstrated that iron and lipid ROS levels were elevated in $\mathrm{I} / \mathrm{R}$ injury and that mitochondria decreased in size and increased in membrane density, which is indicative of ferroptosis. Furthermore, the generation of lipid ROS suggests iron accumulation and glutathione (GSH) depletion. The expression of ferroportin (Fpn) protein and mRNA was decreased in TM4 cells. Notably, overexpression of Fpn inhibited ferroptosis, lipid ROS generation and iron accumulation. In addition, GSH-dependent peroxidase 4 (GPX4) was inactivated via GSH depletion following I/R injury, whereas GPX4 activation blocked I/R-induced ferroptosis by reducing lipid ROS levels. The mitogen-activated protein kinase (MAPK) pathway was also investigated in the present study; it was observed that I/R-induced ferroptosis was blocked by inhibiting p38 MAPK activation. The results of the present study demonstrate that ferroptosis is a pervasive and dynamic type of cell death induced by OGD/R injury in Sertoli cells. This may
\end{abstract}

Correspondence to: Dr Fulu Gao, Department of Histology and Embryology, Hebei Medical University, 361 Zhongshan East Road, Shijiazhuang, Hebei 050017, P.R. China

E-mail: fulugao0311@126.com

*Contributed equally

Key words: ischemia/reperfusion injury, Sertoli cell, ferroptosis, lipid reactive oxygen species, iron, ferroportin provide a novel insight into the application of cytoprotection in testicular I/R damage-induced cell loss.

\section{Introduction}

Testicularischemia/reperfusion(I/R) injury is a common pathophysiological process that occurs with testicular torsion (1). $\mathrm{I} / \mathrm{R}$ results in testis injury and spermatogenesis loss as well as damage to the contralateral side (1). The crucial underlying mechanism responsible for $\mathrm{I} / \mathrm{R}$ in testicular torsion is oxidative stress (2,3). Caspase-independent apoptosis resulting from oxidative stress mediates tissue injury; however, this mechanism is not solely responsible for I/R-induced cell death (4). Ferroptosis is a recently recognized type of non-apoptotic cell death that has been observed in various pathological processes, including heart, kidney and liver I/R injury (4-9). Developing a better understanding of the signaling pathway that induces Sertoli cell death following testicular I/R injury is important for the development of an effective strategy to prevent I/R-induced spermatogenic arrest.

A previous study demonstrated that testicular I/R injury-induced cell death of germ cells, but not Sertoli cells, was inconsistent with spermatogenetic dysfunction (10). Spermatogenesis is a complex process in which spermatogonial stem cells self-renew and differentiate into spermatozoa under coordination of the testicular microenvironment provided by Sertoli cells, which are the only somatic cells located inside the seminiferous epithelium (11). Sertoli cells are major supportive germ cells that regulate spermatogenic cells via a number of paracrine factors $(12,13)$. Germ cell and Sertoli cell interactions are important for male fertility (14). Disrupted Sertoli cell signaling results in germ cell loss and infertility (15). Germ cell loss following testicular I/R injury may result in part from Sertoli cell damage-dependent alterations in the microenvironment (16-18). The mechanism of testicular I/R injury is lipid peroxidation (19). Previous studies have reported that I/R induces ferroptosis in nephritic tubular cells and hepatocytes, whereas other forms of regulated cell death are not observed (7-9). It has been suggested that ferroptosis is a latent mechanism associated with $\mathrm{I} / \mathrm{R}$ injury and oxidative toxicity in cells $(7,20)$. It was therefore hypothesized that oxidative damage may be associated with I/R-induced ferroptosis or cell death in Sertoli cells. The aim of the present study was to explore the potential mechanisms and regulatory factors of 
cell death in testicular Sertoli cells, which may reveal a novel therapeutic strategy for the prevention of I/R-induced cell loss. To the best of our knowledge, no previous studies have investigated the probability and mechanism of I/R-induced ferroptosis in Sertoli cells.

Ferroptosis is distinct from apoptosis, autophagy and necrosis at the biochemical, morphological and genetic levels (4). Ferroptosis serves a major role in acute tissue injury, I/R injury and neurotoxicity $(4,21)$. The major mediators of ferroptosis are lipid peroxidation and iron metabolism signaling (4,22-24). In addition, inducers of ferroptosis may be divided into two categories: i) Inhibitors of cysteine import, which subsequently lead to glutathione (GSH) depletion, and ii) inhibitors of GSH-dependent peroxidase 4 (GPX4). A variety of inhibitors and inducers of ferroptosis have been reported to regulate the accumulation of lethal lipid reactive oxygen species (ROS) derived from iron metabolism turbulence $(4,25,26)$; however, the molecular mechanism underlying the induction of ferroptosis in Sertoli cells remains unknown.

In the present study, an in vitro $\mathrm{I} / \mathrm{R}$ cell model was established using TM4 cells to investigate the induction of ferroptotic cell death and the associated signaling pathway responsible for cell death regulation in Sertoli cells.

\section{Materials and methods}

Reagents. Ferrostatin-1 (Fer-1; cat. no. S7243), liproxstatin-1 (cat. no. S7699), carbobenzoxy-valyl-alanyl-aspartyl-[O-m ethyl]-fluoromethylketone (Z-VAD-FMK; cat. no S7023), necrostatin-1 (cat. no. S8037), 3-methyladenine (3-MA; cat. no. S2767), SB203580 (cat. no. S1076), SP600125 (cat.no. S1460), and SCH772984 (cat. no. S7101) were obtained from Selleck Chemicals (Houston, TX, USA). N-acetyl-cysteine (NAC; cat. no. A0737), deferoxamine (DFO; cat. no. D9533), $\mathrm{FeCl}_{3}$ (cat. no. 157740), buthionine-sulfoximine (BSO; cat. no. 19176), Iron Stain kit (cat. no. HT20), GSH (cat. no. G6013), DNase I (cat. no. AMPD1), hyaluronidase type III (cat. no. H3506), collagenase I (cat. no. C0130), insulin-transferrin-selenium (ITS; cat. no. 00031626), epidermal growth factor (EGF; cat. no. E4127), testosterone (cat. no. T6147), follicle stimulating hormone (FSH; cat. no. I9149), ponasterone (cat. no. P3490), neopterin (cat. no. N3386), diphenyleneiodonium chloride (DPI; cat. no. D2926), diethyldithiocarbamate (DETC; cat. no. 228680), 3-amino-1,2,4-triazole (ATZ; cat. no. A8056), Lipid Peroxidation malondialdehyde (MDA) Assay kit (cat. no. MAK085), Glutathione Peroxidase Cellular Activity Assay kit (cat. no. CGP1), Quantification kit for oxidized and reduced GSH (cat. no. 38185), Iron Assay kit (cat. no. MAK 025), and Caspase 3 Assay kit (cat.no. CASP3C) were obtained from Sigma Aldrich (Merck KGaA, Darmstadt, Germany) The following reagents were purchased from Santa Cruz Biotechnology, Inc. (Dallas, TX, USA): Ferroportin-1 short interfering (si)RNA (cat. no. sc-60634), XCT siRNA (cat. no. sc-76934), GPX-4 siRNA (cat. no. sc-63302), control siRNA (cat. no. sc-37007), siRNA Reagent System (cat. no. sc-45064), ferroportin-1 CRISPR Activation Plasmid (cat. no. sc-424774-ACT), GPx-4 CRISPR Activation Plasmid (cat. no. sc-436949-ACT), GPx-1 CRISPR Activation Plasmid (cat. no. sc-420662-ACT), anti-rabbit/mouse IgG horseradish peroxidase conjugate (HRP; cat. no. sc-2379 and sc-2380) and antibodies against transferrin (Tf; cat. no. sc-393595), transferrin receptor 1/cluster of differentiation 71 (TFR1; cat. no. sc-32272), divalent metal transporter $1 /$ natural resistance-associated macrophage proteins (DMT1; cat.no.sc-166884), ferritin (cat.no.sc-25617), GPX4 (cat. no. sc-166120), ferroportin-1 (Fpn; cat. no. sc-49668), and $\beta$-actin (cat. no. sc-58671). Antibodies against p38 mitogen-activated protein kinase (MAPK; cat. no. 9212), extracellular signal-regulated kinase1/2 (ERK1/2; cat. no. 9102), c-Jun NH2-terminal kinase (JNK; cat. no. 9252), phosphorylated (p)-p38 MAPK (cat. no. 4511), p-ERK1/2 (cat. no. 9101), p-JNK (cat. no. 9255), and XCT (SLC7A11; cat. no. 12691) were purchased from Cell Signaling Technology (Danvers, MA, USA). TRIzol reagent was obtained from Invitrogen (Thermo Fisher Scientific, Inc., Waltham, MA, USA). The reverse transcription (RT) system and One Step SYBR PrimeScript RT-quantitative polymerase chain reaction (PCR) kit (cat. no. RR066) were purchased from Takara Bio, Inc. (Otsu, Japan). CellTiter 96 AQueous Non-Radioactive Cell Proliferation Assay kit (G cat. no. 5421) was obtained from Promega Corp. (Madison, WI, USA).

TM4 cell culture and establishment of cell I/R injury model. TM4 mouse Sertoli cells (cat. no. CM-1912; American Type Culture Collection, Manassas, VA, USA) were cultured in Dulbecco's modified Eagle medium/nutrient mixture F-12 (DMEM/F-12; Gibco; Thermo Fisher Scientific, Inc.) medium supplemented with $5 \%$ fetal bovine serum, $0.1 \%$ ITS, $1 \mu \mathrm{g} / \mathrm{ml}$ EFG, $0.1 \mu \mathrm{M}$ testosterone, $25 \mathrm{U} / 1$ FSH, 100 units $/ \mathrm{ml}$ penicillin, and $100 \mu \mathrm{g} / \mathrm{ml}$ streptomycin at $37^{\circ} \mathrm{C}$ in an atmosphere containing $5 \% \mathrm{CO}_{2}$ for $72 \mathrm{~h}$. The I/R cell model was established as previously described $(27,28)$. TM4 cells were cultured in airtight bottles with ischemic buffer $(5.37 \mathrm{mM} \mathrm{KCl}$, $136.89 \mathrm{mM} \mathrm{NaCl}, 0.44 \mathrm{mM} \mathrm{KH}{ }_{2} \mathrm{PO}_{4}, 0.338 \mathrm{mM} \mathrm{Na}_{2} \mathrm{HPO}_{4}$, $4.166 \mathrm{mM} \mathrm{NaHCO}$, and $5 \mathrm{mM} \mathrm{D-glucose;} \mathrm{pH} 6.8$ ) at $37^{\circ} \mathrm{C}$ in a hypoxic incubator with $5 \% \mathrm{CO}_{2}, 1 \% \mathrm{O}_{2}$ and $94 \% \mathrm{~N}_{2}$ for $2 \mathrm{~h}$. The medium was subsequently removed, normal routine culture was resumed and reoxygenation was initiated, as described above. The I/R cell model was the OGD/R model of TM4 cells. The cells of OGD/R model were set as OGD/R group and normal TM4 cells were set as control group.

Cell transfection. Ferroportin-1 and GPx-4 knockdown was achieved by transfection with siRNA targeting ferroportin-1 and GPx-4 (si-ferroportin-1 and si-GPx-4; Santa Cruz Biotechnology, Inc.) using an siRNA Transfection Reagent (Santa Cruz Biotechnology, Inc.) with a control siRNA as the control (Santa Cruz Biotechnology, Inc.). Overexpression of ferroportin-1 and GPx-4 were achieved by transfection with ferroportin-1, GPx-4 and GPx-1 overexpression vectors (ferroportin-1, GPx-4, and GPx-1 CRISPR Activation Plasmid; Santa Cruz Biotechnology, Inc.) using Plasmid Transfection Medium (Santa Cruz Biotechnology, Inc.), with the CRISPR/Cas9 Plasmid used as the control. At $7 \mathrm{~h}$ post-transfection, the medium was changed to whole medium and cells were cultivated for an additional $24 \mathrm{~h}$. The changes in ferroportin-1, GPx-4, and GPx-1 were measured using RT-qPCR, as described below.

Cell viability assay. Cell viability was analyzed using the CellTiter 96 AQueous Non-Radioactive Cell Proliferation 
Assay kit according to the manufacturer's protocol. TM4 cells were seeded onto 96-well plates $\left(1 \times 10^{3}\right.$ cells/well), and $20 \mu \mathrm{l}$ MTS/phenazine methosulfate was pipetted into each well. The plate was incubated for $2 \mathrm{~h}$ at $37^{\circ} \mathrm{C}$, and then the absorbance was measured at $490 \mathrm{~nm}$ using a Spectramax M2 Multi-Mode Microplate Reader (Molecular Devices, LLC, Sunnyvale, CA, USA) to calculate the percentage of surviving cells.

Caspase-3 activity assay. Caspase-3 activity in TM4 cells was assessed using the Caspase-3 Activity Assay kit according to the manufacturer's protocol.

Lipid ROS measurement. TM4 cells were lysed with MDA lysis buffer from the Lipid Peroxidation malondialdehyde (MDA) Assay kit and centrifuged at $8,000 \mathrm{x}$ g for $10 \mathrm{~min}$ at $4^{\circ} \mathrm{C}$ to remove insoluble material. The level of MDA in TM4 cell lysates was assessed using a Lipid Peroxidation MDA Assay kit according to the manufacturer's protocol. The absorbance was measured at $532 \mathrm{~nm}$ using a spectrophotometer.

GSH content and GPXs activity measurement. The expression of reduced and oxidized forms of GSH was analyzed using a quantification kit for oxidized and reduced GSH according to the manufacturer's protocol. Cultured TM4 cells were washed three times with PBS, 5 min each time mixed with assay buffer and substrate solution from the Quantification kit for oxidized and reduced GSH, and incubated at room temperature in a fluorometer. Absorbance was assessed at $412 \mathrm{~nm}$ and the results were expressed as a percent of the control.

GPX activity in the cell lysates was measured using the Glutathione Peroxidase Cellular Activity Assay kit according to the manufacturer's protocol. The absorbance was measured at 405 or $415 \mathrm{~nm}$ using a microplate reader. The values were expressed as a percentage of non-treated cells.

Intracellular iron measurement. The intracellular iron concentration was measured using an Iron Assay kit according to the manufacturer's protocol. An iron reducer was added to cell lysates to reduce ferric iron $\left(\mathrm{Fe}^{3+}\right)$ to ferrous iron $\left(\mathrm{Fe}^{2+}\right)$ and incubated for $30 \mathrm{~min}$ at room temperature in the dark. The iron reaction produced a colored complex and absorbance was measured at $593 \mathrm{~nm}$.

$R T$-qPCR. Total cellular RNA was isolated from the cells in the control and OGD/R groups using TRIzol (Invitrogen; Thermo Fisher Scientific, Inc.) according to the manufacturer's protocol. The RNA was reverse transcribed $\left(42^{\circ} \mathrm{C}\right.$ for $10 \mathrm{~min}, 95^{\circ} \mathrm{C}$ for $5 \mathrm{~min}, 4^{\circ} \mathrm{C}$ for $3 \mathrm{~min}, 5$ cycles) into cDNA using an RT system. qPCR was performed using a One Step SYBR Green PrimeScript RT-qPCR kit with denaturation at $95^{\circ} \mathrm{C}$ for $15 \mathrm{~min}, 50$ cycles at $95^{\circ} \mathrm{C}$ for $15 \mathrm{sec}, 72^{\circ} \mathrm{C}$ for $15 \mathrm{sec}$, $95^{\circ} \mathrm{C}$ for $30 \mathrm{sec}$ and $60^{\circ} \mathrm{C}$ for $15 \mathrm{sec}$. PCR was performed in triplicate and normalized using the ABI 7500 Real-Time PCR System (Applied Biosystems; Thermo Fisher Scientific, Inc.). The primers used were as follows: Fpn, forward 5'-AGCCAA GATGGCACTAAGCAC-3' and reverse 5'-TCTATGTTATCG AACAGACAT-3'; GPX4, forward 5'-AGCCAAGACCGAAGT AAACTACAC-3' and reverse 5'-GGATCTTCATCCAGTTCC ACAG-3'; GAPDH, forward 5'-CAAGGTCATCCATCCATG ACAACTTTG-3' and reverse 5'-GTCCACCACCCTGTTGCT
GTAG-3'. GAPDH was used as the reference gene. Relative gene expression was analyzed by $2^{-\Delta \Delta \mathrm{Cq}}$ method (28).

Western blot analysis. Cells in the control and OGD/R groups were lysed in cell lysis solution containing $1 \mathrm{mM}$ phenylmethane sulfonyl-fluoride. The total protein concentration was determined with bicinchoninic acid assay kit (Thermo Fisher Scientific, Inc.). Protein lysates ( $40 \mu \mathrm{g} /$ lane) were separated by $10-12 \%$ SDS-PAGE and transferred onto $0.22 \mu \mathrm{m}$ polyvinylidene difluoride membranes (EMD Millipore, Billerica, MA, USA). The membranes were blocked with $3 \%$ bovine serum albumin (Sigma-Aldrich; Merck KGaA) in Tris-buffered saline- $0.05 \%$ Tween (TBST) for $1 \mathrm{~h}$ at $37^{\circ} \mathrm{C}$. Membranes were subsequently incubated with antibodies against Fpn (1:100), GPX4 (1:200), p38 (1:500), p-p38 MAPK (1:500), ERK1/2 (1:500), p-ERK1/2 (1:500), JNK (1:500), p-JNK (1:500), Tf (1:200), TFR1 (1:200), DMT1 (1:200), ferritin (1:100), SLC7A11 $(1: 100)$ and $\beta$-actin $(1: 1,000)$ at $4^{\circ} \mathrm{C}$ overnight. The membranes were washed three times with TBST and incubated with horseradish peroxidase-conjugated goat anti-rabbit/mouse IgG for $1 \mathrm{~h}$ at room temperature the following morning. The blots were visualized using an enhanced chemiluminescence detection kit (Thermo Fisher Scientific, Inc.). The band density of target proteins was quantified and normalized to that of $\beta$-actin using Quantity One software (version 4.6.2, Bio-Rad Corporation, Hercules, CA, USA).

Statistical analysis. All data were processed with the using SPSS 19.0 (IBM Corp., Armonk, NY, USA). Data are presented as the mean \pm standard deviation from three independent experiments. One-way analysis of variance with Tukey's multiple comparison post hoc test was employed for comparison among groups. $\mathrm{P}<0.05$ was considered to indicate a statistically significant difference.

\section{Results}

Ferroptosis is induced following I/R injury in TM4 cells. Testicular I/R injury has been reported to induce cell death in germ cells, but not in Sertoli cells $(19,28,29)$. It was therefore examined whether I/R was able to induce cell death in Sertoli cells. TM4 cells in control and OGD/R groups were analyzed and a notable increase in cell death was observed in the OGD/R group compared with the control $(\mathrm{P}<0.01$; Fig. 1A). I/R stress activates various types of cell death, including apoptosis, necrosis, autophagy, and ferroptosis-mediated cell death (30). Recent studies have indicated that I/R induces ferroptosis, but not other forms of cell death, in nephrotic tubular cells and hepatocytes $(8,31,32)$. Cells were incubated with the cell death inhibitor Z-VAD-FMK, ferroptosis inhibitor Fer-1, necrosis inhibitor necrostatin-1 and autophagy inhibitor 3-MA and cell death was evaluated. The results indicated that OGD/R-induced cell death was ameliorated by Fer-1 compared with the control group ( $\mathrm{P}<0.01$; Fig. 1A); however, no significant effect was observed with inhibitors of apoptosis, necrosis or autophagy. OGD/R did not significantly promote the activity of apoptotic marker caspase 3 (Fig. 1B). The results indicate that ferroptosis serves a role in the accumulation of lipid peroxidation and iron; lipid ROS levels were increased in the OGD/R group compared with the control, and this effect was ameliorated 

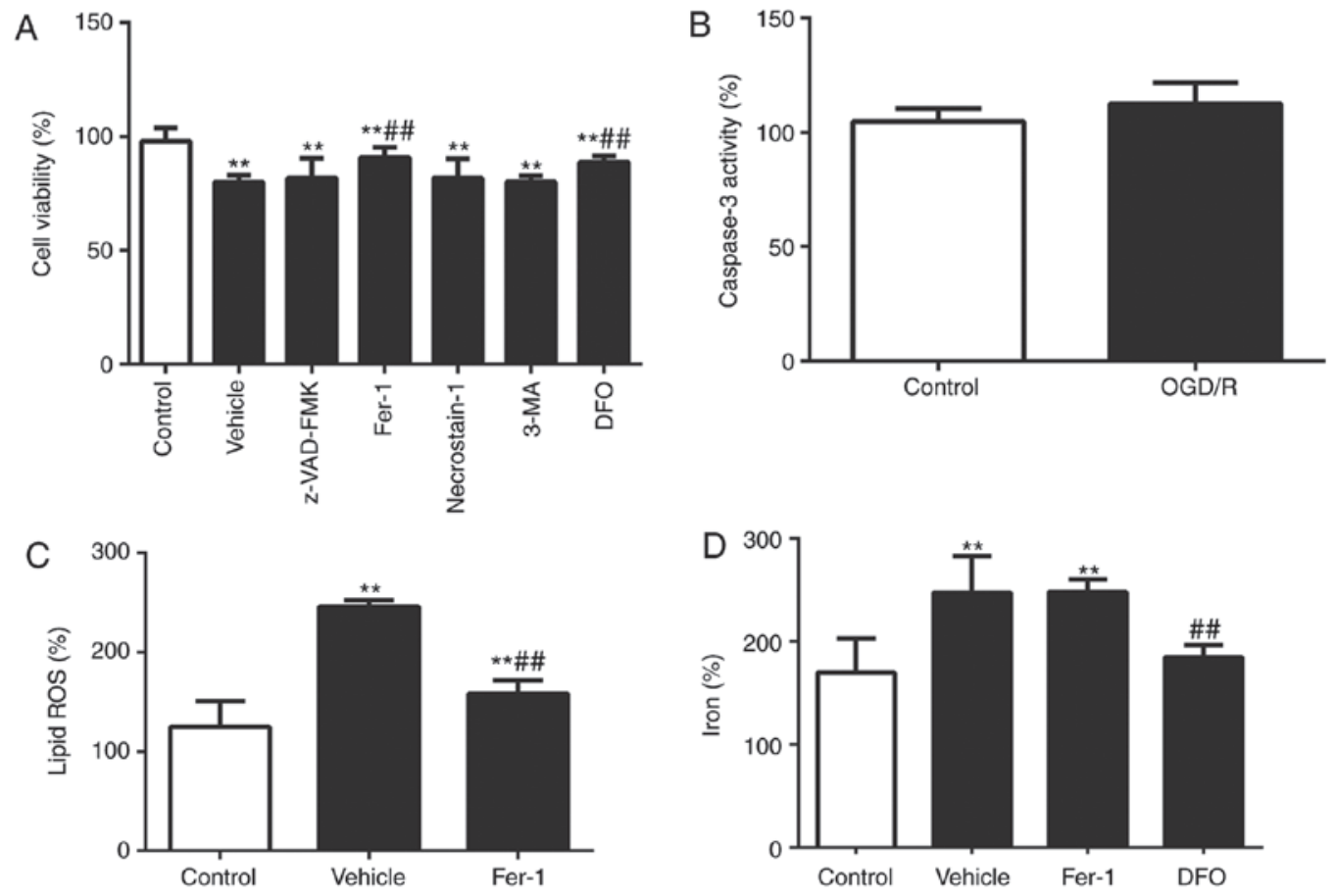

Figure 1. OGD/R-injury induces ferroptosis in TM4 cells. (A) Cell viability was measured at $24 \mathrm{~h}$ following treatment with $50 \mu \mathrm{M}$ Z-VAD-FMK, $50 \mathrm{nM}$ Fer-1, $10 \mu \mathrm{M}$ Necrostatin-1, $50 \mu \mathrm{M}$ 3-MA or $50 \mu \mathrm{M}$ DFO. (B) Caspase 3 activity was measured using a Caspase-3 Activity Assay kit. (C) Lipid peroxidation was assayed following administration of vehicle or Fer-1 in OGD/R group cells. (D) Intracellular iron was analyzed following vehicle, Fer-1 or DFO treatment. $\mathrm{n}=6$. ${ }^{* *} \mathrm{P}<0.01$ vs. control and ${ }^{\# \#} \mathrm{P}<0.01$ vs. vehicle. OGD/R, oxygen-glucose deprivation/reoxygenation; Z-VAD-FMK, carbobenzoxy-valyl-alanyl-aspartyl-[O-meth yl]-fluoromethylketone; Fer-1, ferrostatin-1; 3-MA, 3-methyladenine; DFO, deferoxamine.
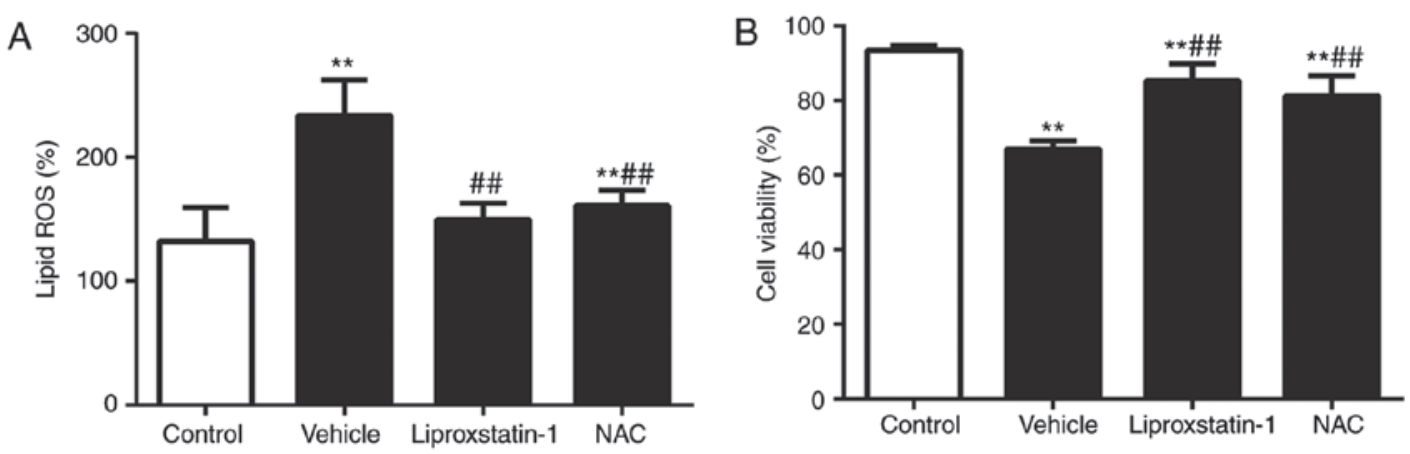

Figure 2. Lipid peroxidation regulates OGD/R-triggered ferroptotic cell death in TM4 cells. (A) Lipid peroxidation was assayed following vehicle, Liproxstatin-1 or NAC treatment in OGD/R group cells. (B) Cell viability of TM4 cells was assessed $24 \mathrm{~h}$ following vehicle, Liproxstatin-1 or NAC treatment in OGD/R group cells. $\mathrm{n}=6 .{ }^{* *} \mathrm{P}<0.01$ vs. control and ${ }^{\# \#} \mathrm{P}<0.01$ vs. vehicle. OGD/R, oxygen-glucose deprivation/reoxygenation; $\mathrm{NAC}, \mathrm{N}$-acetyl-cysteine.

by Fer-1 $(\mathrm{P}<0.01$; Fig. 1C). To evaluate the effect of iron on OGD/R-induced cell death, the iron chelator DFO was used to treat Sertoli cells; the results demonstrated that cell death and iron levels were reduced ( $\mathrm{P}<0.01$; Fig. $1 \mathrm{~A}$ and $\mathrm{D})$. Taken together, these results suggest that ferroptosis contributes to OGD/R-induced growth inhibition in Sertoli cells, whereas cell death, necroptosis and autophagy do not.

Lipid peroxidation regulates $O G D / R$-induced ferroptotic cell death. Prior studies have reported that ferroptosis is characterized by an increase in lethal lipid peroxidation products, which exhibit cytotoxicity $(4,33)$. Lipid ROS levels were assessed and the results revealed that lipid ROS were significantly increased in the OGD/R group compared with the control group $(\mathrm{P}<0.01$; Fig. 2A). Lipid ROS generation was inhibited by liproxstatin-1 and NAC. Liproxstatin-1 and NAC both significantly reduced ROS generation ( $\mathrm{P}<0.01$; Fig. $2 \mathrm{~A}$ ). It was also observed that NAC and liproxstatin-1 effectively inhibited cell death $(\mathrm{P}<0.01 ;$ Fig. $2 \mathrm{~B})$. These results suggest that lipid ROS is required for OGD/R-induced ferroptotic cell death.

Lipid peroxidation results from the accumulation of iron and depletion of GSH. The production of lipid ROS is required for ferroptosis and is associated with multiple processes, including NADPH-mediated lipid peroxidation, iron-dependent ROS generation through the Fenton reaction and GSH depletion $(4,23,25)$. To ascertain whether NADPH oxidases contribute to lipid ROS production, TM4 cells were treated with NADPH oxidase inhibitors, neopterin and DPI; lipid ROS levels were unaffected. However, treatment with the iron 

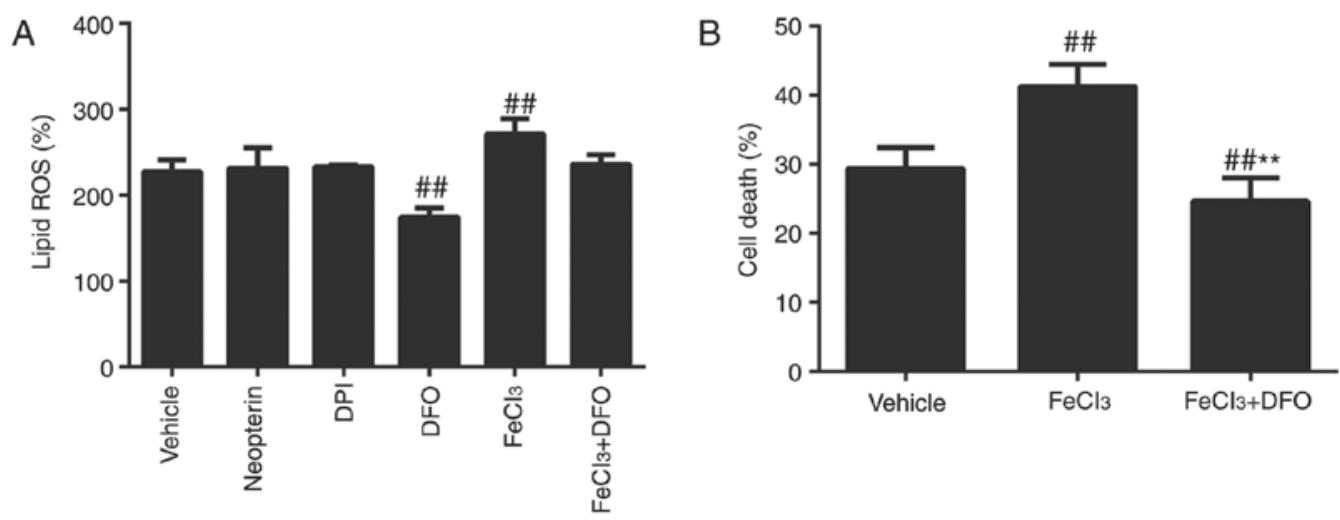

Figure 3. Lipid peroxidation results from the accumulation of iron in TM4 cells. (A) Lipid ROS was analyzed following treatment with vehicle, Neopterin, DPI, DFO, $5 \mu \mathrm{M} \mathrm{FeCl}_{3}$ or $50 \mu \mathrm{M} \mathrm{FeCl}_{3}+\mathrm{DFO}$ for $12 \mathrm{~h}$ in OGD/R group cells. (B) Cell death was quantified following the administration of vehicle, $\mathrm{FeCl} 3$ or $\mathrm{FeCl} 3$ plus DFO in $\mathrm{I} / \mathrm{R}$ group cells for $12 \mathrm{~h}(\mathrm{n}=6)$. Values are expressed as the mean \pm standard deviation. ${ }^{* \#} \mathrm{P}<0.01$ vs. vehicle and ${ }^{* *} \mathrm{P}<0.01$ vs. $\mathrm{FeCl} \mathrm{l}_{3}$. ROS, reactive oxygen species; DPI, diphenyleneiodonium chloride; DFO, deferoxamine; OGD/R, oxygen-glucose deprivation/reoxygenation.
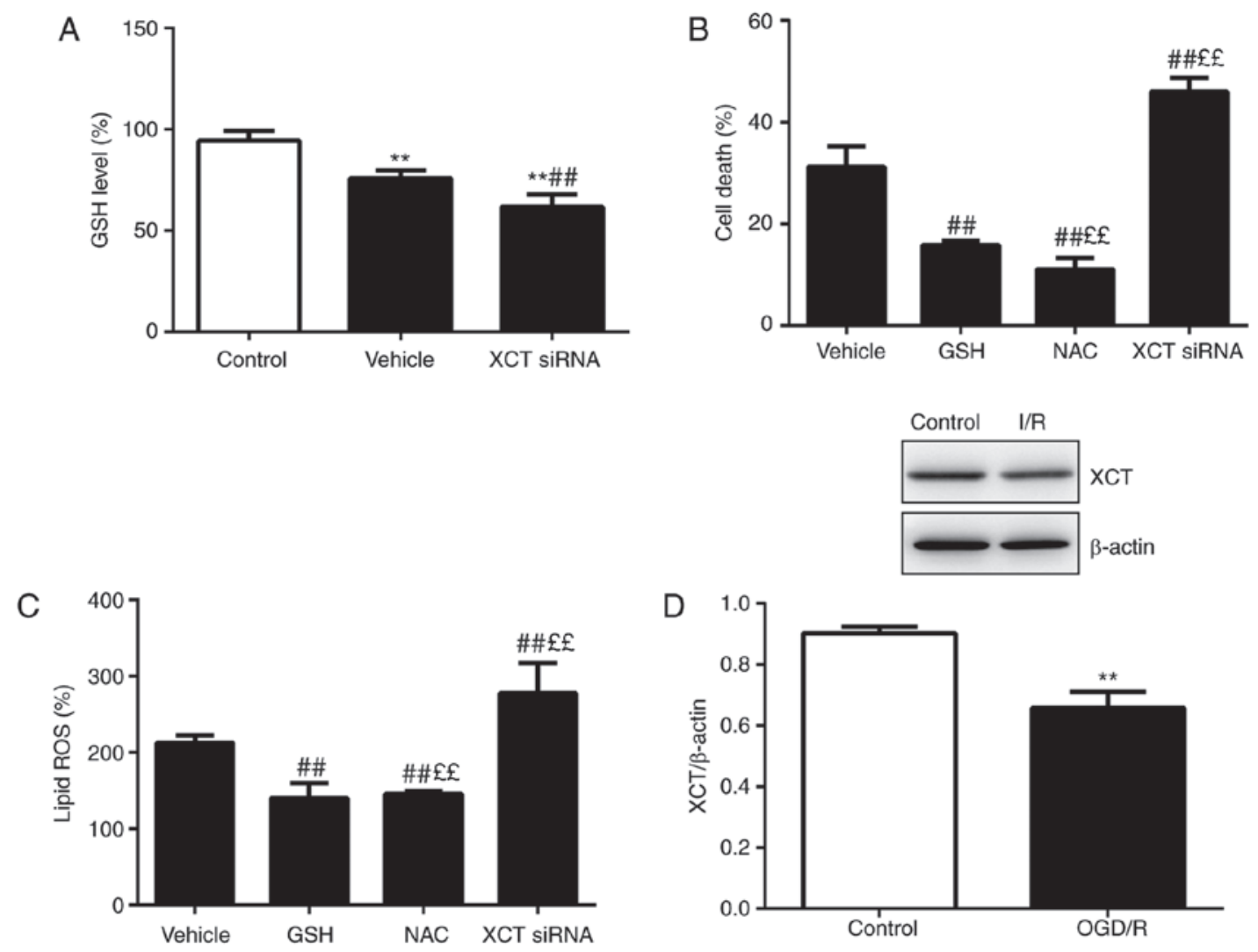

Figure 4. Lipid peroxidation results from GSH depletion. (A) GSH levels were determined following treatment with vehicle or XCT siRNA administration. (B) Cell death was analyzed following treatment with vehicle, GSH $(5 \mathrm{mM})$, NAC $(5 \mathrm{nM})$ or XCT siRNA for $24 \mathrm{~h}(\mathrm{C})$ Lipid ROS was assessed following treatment with vehicle, GSH, NAC or XCT siRNA treatment for $12 \mathrm{~h}$. (D) XCT expression was assessed using western blotting. $\mathrm{n}=6$. ${ }^{* *} \mathrm{P}<0.01 \mathrm{vs}$. control, ${ }^{\text {ff }} \mathrm{P}<0.01$ vs. GSH and ${ }^{\# \#} \mathrm{P}<0.01$ vs. vehicle. GSH, glutathione; si, small interfering; NAC, N-acetyl-cysteine; ROS, reactive oxygen species; OGD/R, oxygen-glucose deprivation/reoxygenation.

chelator DFO effectively blocked OGD/R-induced lipid ROS production $(\mathrm{P}<0.01$; Fig. 3A) compared with untreated cells, suggesting that lipid ROS generation is associated with iron content. Recent studies have demonstrated that iron overload injures Sertoli cells (34). Cells were subsequently treated with exogenous $\mathrm{Fe}\left(\mathrm{FeCl}_{3}\right)$ to confirm that iron affected OGD/R-induced ferroptosis and the results revealed that lipid ROS levels and cell death were further increased $(\mathrm{P}<0.01$; Fig. 3A and B). A reduction in lipid ROS levels and cell death was also observed in cells cultured with DFO compared with the vehicle $(\mathrm{P}<0.01$; Fig. $3 \mathrm{~A}$ and $\mathrm{B})$. These data suggest that ROS production results from iron accumulation and that iron may serve a crucial role in OGD/R-induced ferroptosis.

To explore whether lipid ROS generation partially reflects GSH depletion, GSH levels in cells were assessed. GSH content was significantly reduced in the OGD/R group compared with the control $(\mathrm{P}<0.01$; Fig. 4). Cells were treated with GSH or the GSH precursor NAC and cell viability and lipid ROS 

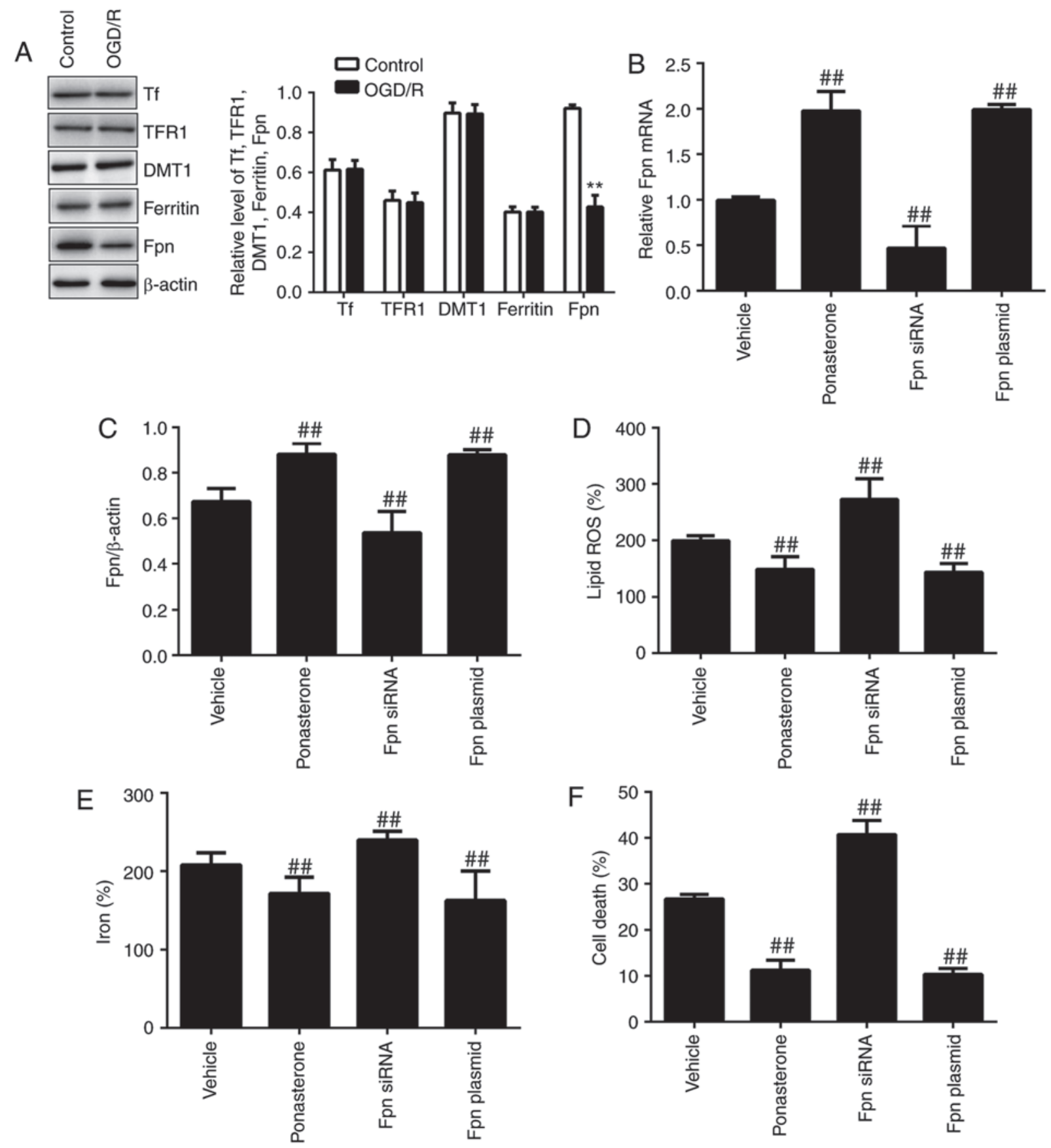

Figure 5. Overexpression of Fpn rescues OGD/R-induced ferroptosis via suppression of iron accumulation. (A) Protein levels of Tf, TFR1, DMT1, ferritin and Fpn were analyzed using western blotting. TM4 cells were incubated with vector, ponasterone $(10 \mu \mathrm{M})$, Ferroportin-1 siRNA or Ferroportin-1 CRISPR Activation Plasmid. (B) Fpn mRNA expression, (C) Fpn protein expression, (D) lipid ROS levels, (E) iron levels and (F) cell death were assessed. ${ }^{* *} \mathrm{P}<0.01$ vs. control, and ${ }^{\# \# / P} \mathrm{P}<0.01$ vs. vehicle. Fpn, ferroportin; OGD/R, oxygen-glucose deprivation/reoxygenation; TF, transferrin; TFR1, transferrin receptor $1 /$ cluster of differentiation; DMT1, divalent metal transporter 1/natural resistance-associated macrophage proteins; si, small interfering; ROS, reactive oxygen species.

levels were assessed. The results revealed that GSH or NAC treatment significantly prevented OGD/R-induced lipid ROS generation $(\mathrm{P}<0.01)$, whereas GSH had no significant effect on OGD/R-induced cell death (Fig. 4B and C). It was also observed that the protein level of XCT (SLC7A11), a cysteine transport receptor, was reduced following $\mathrm{OGD} / \mathrm{R}$ injury $(\mathrm{P}<0.01$; Fig. 4D). Furthermore, siRNA-mediated knockdown of XCT, the upstream activator of GSH, reduced the GSH content and markedly increased cell death and lipid ROS levels $(\mathrm{P}<0.01$; Fig. 4A-C). These data indicate that GSH depletion is consistent with OGD/R-induced production of lipid ROS, resulting in ferroptosis. These findings suggest that ROS generation results from iron accumulation and GSH depletion.

Overexpression of Fpn rescues $O G D / R$-induced ferroptosis via suppression of iron accumulation. Increased iron uptake and reduced iron output through iron metabolism proteins both lead to iron overload during the ferroptotic cell death process $(4,35)$. First, it was determined which iron regulatory proteins were expressed in Sertoli cells using immunocytochemistry and western blotting. As presented in Fig. 5A, the following factors were expressed as normal in Sertoli cells: Tf, 

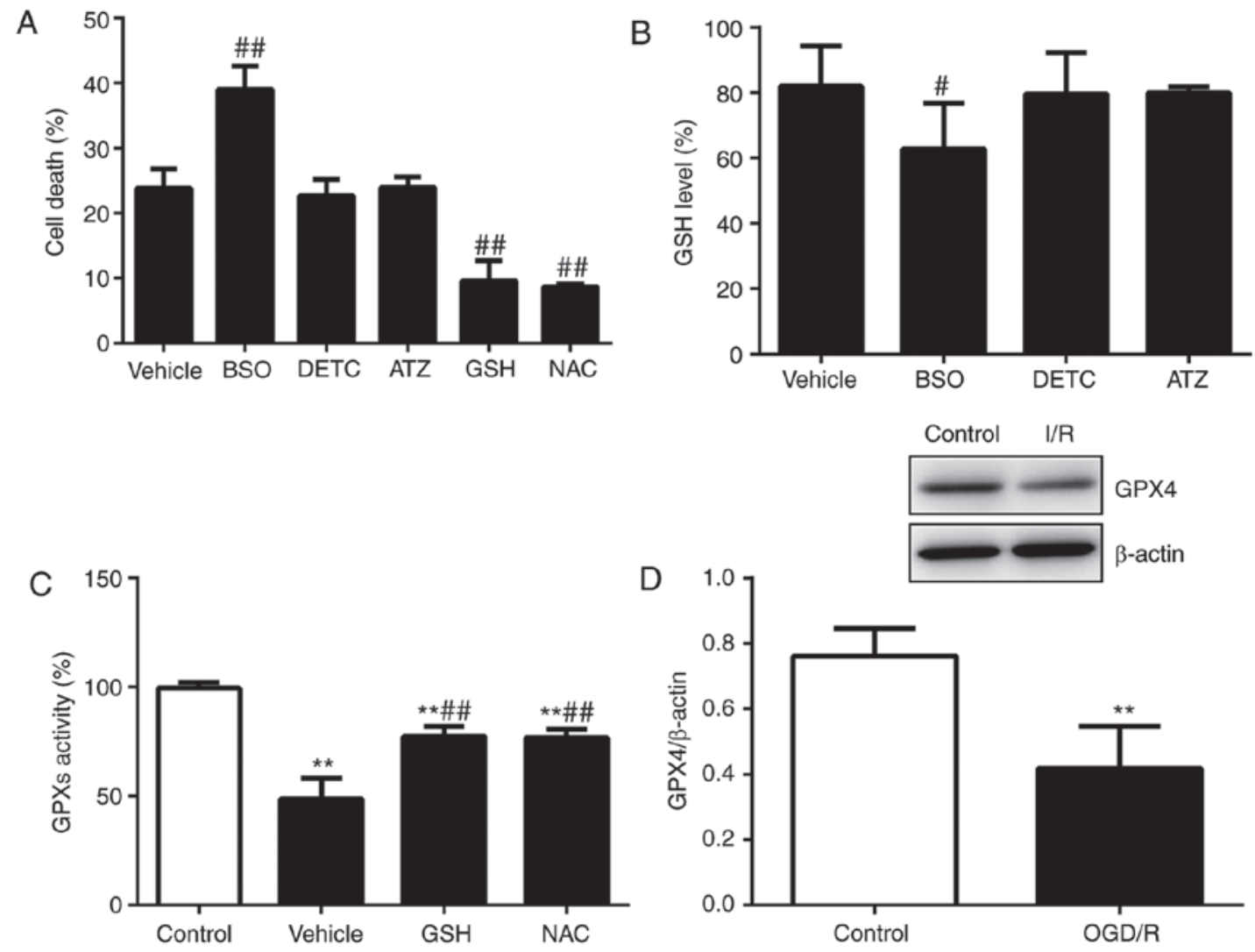

Figure 6. GPX4 is inactivated following testicular OGD/R injury via GSH depletion. (A) Cell death was assessed following treatment with vector, BSO $(50 \mathrm{nM})$, DETC $(10 \mathrm{nM})$ or ATZ $(10 \mu \mathrm{M})$ for $24 \mathrm{~h}$. (B) GSH levels were analyzed following treatment with vector, BSO (50 nM), DETC (10 nM), ATZ (10 $\mu \mathrm{M})$, GSH $(5 \mathrm{mM})$ or NAC $(5 \mathrm{nM})$ for $12 \mathrm{~h}$. (C) Activities of GPXs were examined following treatment with vehicle, GSH or NAC for $6 \mathrm{~h}$. (D) GPX4 protein expression was analyzed using western blotting. $\mathrm{n}=6 .{ }^{* *} \mathrm{P}<0.01$ vs. control, ${ }^{\#} \mathrm{P}<0.05$ and ${ }^{\# \#} \mathrm{P}<0.01$ vs. vehicle. GSH, glutathione; GPX4, GSH-dependent peroxidase 4; $\mathrm{OGD} / \mathrm{R}$, oxygen-glucose deprivation/reoxygenation; BSO, buthionine-sulfoximine; DETC, diethyldithiocarbamate; ATZ, 3-amino-1,2,4-triazole.

which binds ferric iron $\left(\mathrm{Fe}^{3+}\right)$; TFR1, which imports iron into cells; DMT1, which mediates ferrous iron $\left(\mathrm{Fe}^{2+}\right)$ release into the cytoplasm; cytosolic ferritin, which stores excess iron; and the membrane protein Fpn, which mediates iron export (35). The expression of Fpn was markedly reduced in the OGD/R group $(\mathrm{P}<0.01)$, and no alterations were observed in the expression of Tf, TFR1, DMT1 or ferritin. These results indicate that OGD/R may reduce iron export to induce ferroptosis by decreasing Fpn expression. Previous studies have revealed that Fpn mutation may lead to iron overload and subsequent diseases accompanied by normal or low transferrin expression $(4,36)$. To further demonstrate whether Fpn inhibits OGD/R-induced lipid ROS and ferroptosis, Sertoli cells were transfected with the Ferroportin-1 CRISPR Activation Plasmid, treated with the Fpn activator ponasterone and subsequently analyzed for ROS and iron levels. Cells transfected with the Ferroportin-1 CRISPR activation plasmid or treated with ponasterone exhibited increased protein and mRNA expression of Fpn and blocked accumulation of lipid ROS and iron $(\mathrm{P}<0.01$; Fig. 5). Cell death was also significantly decreased $(\mathrm{P}<0.01$; Fig. 5F). By contrast, knockdown of Fpn with ferroportin-1 siRNA increased the OGD/R-induced lipid ROS level and iron content, but not cell death $(\mathrm{P}<0.01$; Fig. 5D-F). Taken together, these results indicate that Fpn overexpression inhibited OGD/R-induced ferroptosis in Sertoli cells by reducing the content of iron and generation of lipid ROS and that the Fpn inducer ponasterone served the same role.
GPX4 is inactivated following OGD/R injury via GSH depletion. Considering that GSH depletion is crucial for OGD/R-induced ROS generation, it was examined how OGD/R-induced GSH depletion may lead to ferroptosis in Sertoli cells. The cells were treated with the GSH synthesis inhibitor BSO and antioxidant inhibitors, including the superoxide dismutase (SOD) inhibitor DETC and the catalase inhibitor ATZ, and subsequently, examined for cell death and GSH levels. The results revealed that inhibitors induced cell death and that the GSH content was not significantly reduced by these antioxidant inhibitors compared with BSO (Fig. 6A and B). The results indicated that altered downstream GSH depletion was likely responsible for the induction of ferroptotic cell death. It was considered that GPX4 inactivation due to GSH depletion induces ferroptosis by accumulating lipid ROS from lipid peroxidation. Previous studies have demonstrated that GPX4 regulates ferroptosis via indirect or direct targeting of lipid peroxidation and iron metabolism (4). Furthermore, inactivation of GPX4 triggers ferroptotic cell death in renal tubular epithelial cells via lipid peroxidation $(24,37,38)$. To determine whether GPX4 expression is decreased in the cell model of OGD/R-induced testicular damage, the total activity of GPXs was examined as well as GPX4 expression using Western blotting. Notable decreases in GPXs activity and GPX4 expression were observed ( $<<0.01$; Fig. $6 \mathrm{C}$ and D). Furthermore, treatment with GSH or NAC revealed that these molecules may activate GPXs ( $\mathrm{P}<0.01$; Fig. 6C). These results 

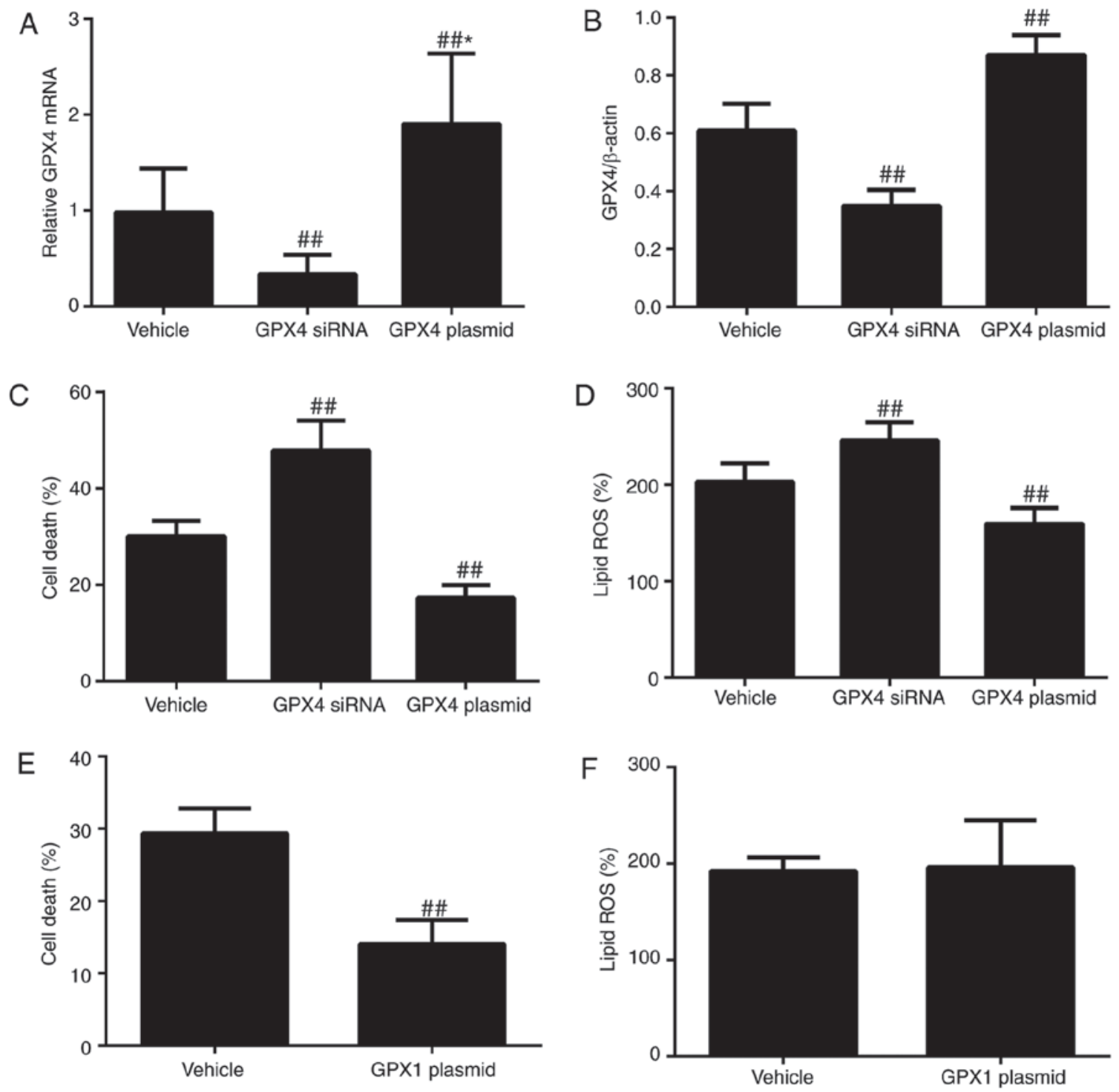

Figure 7. Activation of GPX4 blocks OGD/R-induced ferroptosis via reducing lipid ROS. Cells were incubated with vehicle, GPX-4 siRNA, or GPx-4 CRISPR Activation Plasmid. (A) GPX4 mRNA and (B) protein expression was analyzed and (C) cell death and (D) lipid ROS levels were assayed. Cells were transfected with vector or GPx-1 CRISPR Activation Plasmid, following which (E) cell death and (F) lipid ROS levels were analyzed. $\mathrm{n}=6$. ${ }^{\# \#} \mathrm{P}<0.01 \mathrm{vs}$. vehicle and ${ }^{*} \mathrm{P}<0.01$ vs. GPX4 siRNA. GSH, glutathione; GPX, GSH-dependent peroxidase; OGD/R, oxygen-glucose deprivation/reoxygenation; ROS, reactive oxygen species; si, small interfering.

further indicate that GSH depletion inactivates GPXs with low GPX4 protein expression, resulting in the production of lipid ROS.

Activation of GPX4 blocks OGD/R-induced ferroptosis via reducing lipid ROS. GPX4 has been described as the major regulator of erastin-induced cancer cell ferroptosis and OGD/R-induced ferroptotic renal tubular epithelial cell death (24,37,39-41). A previous study demonstrated that GPX4 is a prerequisite for sperm development (42). It was therefore investigated whether GPX4 regulates OGD/R-induced ferroptotic cell death in Sertoli cells. The results revealed that knocking down GPX4 with GPX-4 siRNA reduced the mRNA and protein levels of GPX4 and increased cell death as well as lipid ROS compared with a vector $(\mathrm{P}<0.01$; Fig. 7A-D). GPX4 expression was subsequently upregulated in cells using the GPx-4 CRISPR Activation Plasmid and it was observed that GPX4 mRNA and protein levels were increased and OGD/R-induced ferroptosis and lipid ROS were decreased $(\mathrm{P}<0.01$; Fig. 7A-D). The role of GPX1, a soluble hydroperoxide reducer, was also examined. GPX1 overexpression partially inhibited OGD/R-induced cell death without affecting lipid ROS generation (Fig. 7E and F), indicating that GPX1 may not scavenge additional ROS species. Taken together, these data indicate that GPX4 is inactivated following testicular OGD/R injury via GSH depletion and blocks OGD/R-induced ferroptosis by reducing lipid ROS.

Inactivation of p38 MAPK prevents $O G D / R$-induced ferroptosis. Previous studies have reported that MAPK signaling is associated with erastin-induced ferroptosis in cancer cells and OGD/R-induced testicular injury $(4,43,44)$. However, whether the MAPK signaling pathway serves a role in OGD/R-induced ferroptosis in Sertoli cells remains 

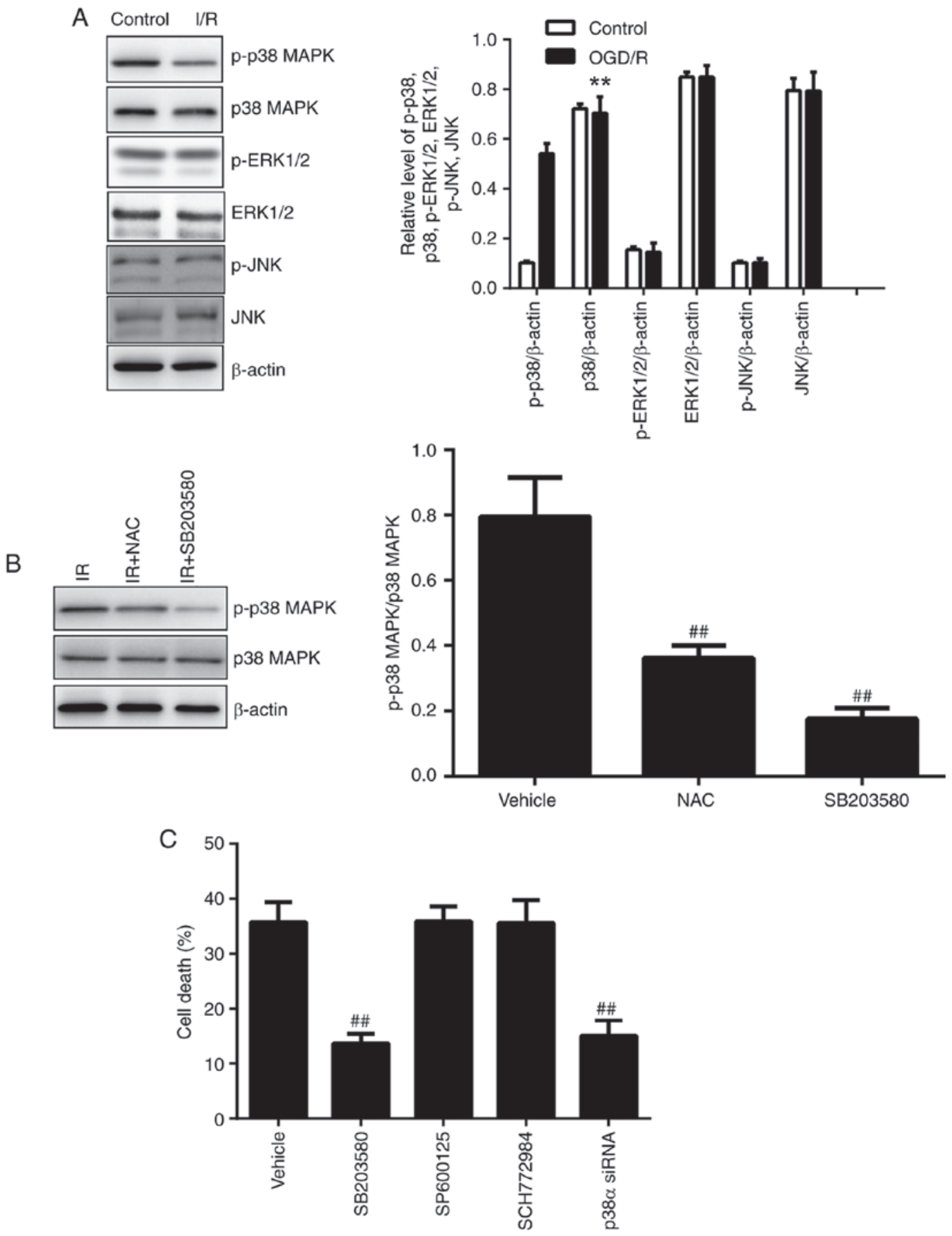

Figure 8. Effect of p38 MAPK on OGD/R-induced ferroptosis in TM4 cells. (A) p38 MAPK, p-p38 MAPK, ERK1/2, p-ERK1/2, JNK and p-JNK were analyzed using western blotting. (B) Comparative levels of p-p38 MAPK/p38 MAPK were detected following treatment with vehicle, NAC or SB203580 using western blotting. (C) Cell death was assessed following treatment with vehicle, SB203580, SP600125, SCH772984 or p38 $\alpha$ siRNA administration. $\mathrm{n}=6$. ${ }^{* *} \mathrm{P}<0.01$ vs. control and ${ }^{\# \#} \mathrm{P}<0.01$ vs. vehicle MAPK, mitogen-activated protein kinase; OGD/R, oxygen-glucose deprivation/reoxygenation; $\mathrm{p}$, phosphorylated; ERK, extracellular-regulated kinase; JNK, c-Jun N-terminal kinase; si, small interfering.

unclear. Three major MAPKs, p38 MAPK, ERK1/2 and JNK, which are involved in I/R-induced ferroptosis, were investigated. OGD/R promoted the phosphorylation of $\mathrm{p} 38$, but not JNK and ERK1/2 (P<0.01; Fig. 8A). In addition, NAC prominently depressed OGD/R-induced p38 MAPK phosphorylation $(\mathrm{P}<0.01$; Fig. $8 \mathrm{~B})$. Cells were treated with the p38 activation inhibitor SB203580, JNK phosphorylation inhibitor SP600125 or ERK1/2 upstream activator inhibitor SCH772984 for $1 \mathrm{~h}$ and subsequently examined. OGD/R-induced cell death was blocked by SB203580 ( $<<0.01$;
Fig. $8 \mathrm{C}$ ), indicating that $\mathrm{p} 38$ MAPK may be associated with OGD/R-induced ferroptosis in Sertoli cells. By contrast, SP600125 and SCH772984 had no effect on OGD/R-induced cell death (Fig. 8C). The OGD/R-induced p38 phosphorylation was notably inhibited by SB203580 (P<0.01; Fig. 8B). Furthermore, knocking down a major isoform of p38 using p38 $\alpha$ siRNA reversed OGD/R-induced ferroptosis in Sertoli cells $(\mathrm{P}<0.01$; Fig. $8 \mathrm{C})$. Collectively, these results suggest that p38 MAPK participates in OGD/R-induced ferroptotic cell death. 


\section{Discussion}

The loss of spermatogenic cells contributes to the poor therapeutic effect of acute testicular I/R injury, highlighting the medical need for new clinical treatment strategies to prevent spermatogenesis arrest. In I/R injury, testicular tissues, including germ cells and Sertoli cells, exhibit high levels of lipid ROS and antioxidant adaptation mechanisms, which renders these tissues susceptible to anti-lipid peroxidation-targeting treatments $(2,44,45)$. In the present study, the type of cell death induced by OGD/R injury and the potential regulating mechanisms of cell death in TM4 cells was assessed using a Sertoli cell line in vitro. The results provide evidence that lipid peroxidation production induced by OGD/R stress leads to the death of Sertoli cells. The main form of cell death following testicular $I / R$ injury was demonstrated to be ferroptosis, resulting from iron accumulation and GSH depletion. Overexpression of Fpn, activation of GPX4 and inactivation of p38MAPK blocked OGD/R-induced ferroptosis in TM4 cells.

Oxidative stress and lipid peroxidation are considered to be fatal contributors to the pathophysiological process of testicular I/R injury (2). In the testes, lipid peroxidation results in oxidative damage and cytotoxicity to germ cells and Sertoli cells, inducing massive apoptosis-mediated germ cell death $(2,19,29,46-48)$. Considering the yet-uncharacterized role of I/R injury-induced lipid peroxidation in Sertoli cell death, the modality of TM4 cell death was investigated. The results confirmed that the pathological process of OGD/R-induced cell injury is similar to that of clinical tissue damage resulting from organic I/R injury; cellular I/R injury is also mediated by lipid ROS generation (49-51). It has previously been demonstrated that $\mathrm{OGD} / \mathrm{R}$ increases lipid peroxidation, intracellular iron levels and cell death in human neuroblastoma cell lines and that cell death is not inhibited by inhibitors of apoptosis, necrosis or autophagy (52). In the present study, it was observed that $\mathrm{OGD} / \mathrm{R}$ promotes cell death, lipid ROS generation and iron accumulation in TM4 cells without activating caspase 3 . These findings are consistent with those previously reported (52). Iron has been demonstrated to mediate lipid peroxidation-induced ferroptotic cell death by supplying lipid ROS, which may be reduced by antioxidants and ferroptosis inhibitors (4). In the present study, it was observed that the antioxidant NAC, a ROS scavenger, reduced lipid ROS levels via inhibiting lipid peroxidation to prevent OGD/R-induced ferroptosis. The effect of ferroptosis has been estimated in various diseases using the small-molecule ferroptosis inhibitor, Fer-1, which acts as a lipid ROS scavenger and suppresses ferroptosis but not apoptosis, necrosis or autophagy $(4,23,25,53)$. In the present study, treatment with Fer-1 significantly depressed OGD/R-induced cell death and lipid ROS generation, indicating that lipid peroxidation may be associated with OGD/R-induced cell death in TM4 cells. Testicular OGD/R injury shares some characteristics with classical I/R-induced damage, including apoptosis-mediated germ cell death and lipid ROS generation, concomitant with persisting Sertoli cell populations and Leydig cell functions $(54,55)$. The results of the present study indicate that OGD/R injury induces ferroptosis in TM4 cells and that lipid ROS generation contributes to the pathogenesis of I/R injury. In vitro studies have demonstrated that liproxstatin-1, a specific inhibitor of ferroptosis that prevents cell death-induced ferroptosis revulsants, alleviates acute renal failure induced by Gpx4 depletion by restraining ferroptotic cell death, whilst also increasing the survival of hepatocytes by blocking lipid peroxidation (6). In the present study, it was confirmed that liproxstatin-1 ameliorates ferroptotic cell death and OGD/R-induced lipid ROS generation in TM4 cells. These results suggest that Sertoli cells are susceptible to OGD/R-induced ferroptosis, confirming the role of lipid peroxidation in and highlighting the effect of ferroptosis inhibitors and antioxidants in improving testicular I/R-induced cell loss.

Previous studies have provided evidence that ferroptosis serves a major role in I/R-induced tissue and cell damage, and that targeting ferroptotic pathways may improve protection against I/R injury (4-9,21). Ferroptosis is a non-apoptotic form of regulated cell death triggered by inactivation of the lipid repair enzyme GPX4 and subsequent lipid peroxidation $(4,37,39,40)$. Lipid peroxidation has routinely been described as a key factor that may lead to spermatogenesis disturbance by damaging Sertoli cells in testicular I/R injury $(16,56)$. Iron-dependent lipid ROS-mediated I/R-induced renal cell ferroptosis and ROS generation-mediated OGD/R-induced Sertoli cell dysfunction have also been reported $(4,16,17,22-24,28,57)$. The essential role of the GSH/GPX4 axis in impeding lipid peroxidation-induced acute renal impairment and associated ferroptotic cell death has been described (6). In the present study, similar findings were obtained in the mouse testicular Sertoli cell line, TM4. Reduced GSH serves a role in antioxidant defense, and the GSH-GPX4 interaction is critical for the regulation of redox (22). Depletion of GSH, a basal cofactor of GPXs, impairs GPX4 function, leading to cellular redox state changes and ferroptosis $(4,22)$. Previous studies have reported that inactivation of GPX4 or degradation of GPX4 induces ferroptosis in vitro $(58,59)$. Knocking out GPX4 in mice results in tissue damage that is associated with the induction of ferroptosis (6). GPX4 has also been demonstrated to protect cells from apoptosis $(37,38)$ and necroptosis $(39)$, suggesting that it serves a protective role in programmed cell death. In the present study, OGD/R-mediated ferroptosis resistance was achieved via upregulation of the GSH-GPX4 pathway. Similarly, knockdown of GPX4-induced ferroptosis and lipid ROS generation, as well as treatment with GSH or NAC, significantly inhibited cell death in TM4 cells. These results suggest that by reducing lipid ROS levels, GPX4 prevents cell death by actively depressing ferroptosis in TM4 cells

Ferroptosis is characterized by the accumulation of lipid ROS derived from iron overload and may be prevented using an iron chelator; this indicates that iron-mediated lipid ROS generation regulates ferroptosis in addition to GSH/GPX4-dependent lipid peroxidation $(4,6,59)$ Excess iron increases lipid ROS through the Fenton reaction, thereby leading to cell death $(4,59)$. Previous studies have verified that, in germ cells, the lethal lipid peroxidation reaction is accelerated by intracellular iron, whereas other divalent cationic metals have no effect (60-62). In the present study, it was observed that I/R stress induced Sertoli cell ferroptosis via the accumulation of iron and lipid peroxidation products. This is consistent with a previous study in which it was demonstrated that iron overload injured Sertoli cells in mice $(34,63)$. Iron 
metabolism signaling associated with the absorption, transport, storage, utilization and export of iron is essential for ferroptosis $(4,6)$. In the present study, OGD/R injury-induced cell death was depressed by the iron chelator DFO or genetic inhibition of cellular iron exclusion, suggesting that intracellular iron overload is a key factor leading to ferroptosis. The role of Sertoli cells in iron acquisition of developing spermatocytes has also been documented (64). In testicular seminiferous tubules, iron circulation through Fpn is reduced in Sertoli cells during iron overload and developing germ cells are protected from iron excess (64-66). Recent studies have reported that $\mathrm{Tf}$ is essential for ferroptosis and may be vital in I/R-induced heart injury (5). However, no alterations in the expression of $\mathrm{Tf}$ and ferritin were observed in the present study. The discrepancy between these findings may reflect differences in the unique iron metabolism process in Sertoli cells. These results suggest that iron regulation through Fpn is altered in TM4 cells and may be a target for testicular I/R injury treatment.

The molecular mechanism underlying OGD/R-induced ferroptosis in Sertoli cell has not yet been explored. The MAPK signaling pathway has been implicated in OGD/R-induced ferroptosis, in addition to iron metabolism and lipid peroxidation $(4,6,59)$. Previous studies have demonstrated that lipid ROS activates the p38 MAPK and JNK pathways and subsequently triggers ferroptosis $(4,58)$. In the present study, it was confirmed that OGD/R injury activates p38 MAPK, but not ERK1/2 and JNK in TM4 cells. A p38 MAPK inhibitor (SB203580) was also demonstrated to prevent OGD/R-induced cell ferroptosis, similar to the antioxidant NAC, confirming the effect of $\mathrm{p} 38$ MAPK in ferroptosis. In addition, siRNA experiments against p38 MAPK were performed to further confirm the role of p38 MAPK in OGD/R-induced ferroptosis in TM4 cells. Transfection with p38 siRNA reduced OGD/R-induced cell death. Furthermore, OGD/R-induced activation of p38 MAPK was depressed by NAC. Collectively, these results suggest that activation of the p38 MAPK signaling pathway contributes to ferroptosis in TM4 cells.

The result s of the present study demonstrate that depressing lipid ROS generation, overexpressing Fpn, activating GPX4, or inactivating p38 MAPK may prevent OGD/R-induced ferroptosis in Sertoli cells. Accordingly, these results may be used as a clinical basis for the development of new efficacious treatments for testicular I/R-induced cell loss and male infertility.

\section{Acknowledgements}

This study was supported by the National Natural Science Foundation of China (grant no. 81373787) and the Hebei Provincial Natural Science Fund (grant no. H2013201139).

\section{Competing interests}

The authors declare that they have no competing interests.

\section{References}

1. Dokmeci D: Testicular torsion, oxidative stress and the role of antioxidant therapy. Folia Med (Plovdiv) 48: 16-21, 2006.
2. Shimizu S, Tsounapi P, Dimitriadis F, Higashi Y, Shimizu T and Saito M: Testicular torsion-detorsion and potential therapeutic treatments: A possible role for ischemic postconditioning. Int J Urol 23: 454-463, 2016.

3. Turner TT, Bang HJ and Lysiak JL: The molecular pathology of experimental testicular torsion suggests adjunct therapy to surgical repair. J Urol 172: 2574-2578, 2004.

4. Xie Y, Hou W, Song X, Yu Y, Huang J, Sun X, Kang R and Tang D: Ferroptosis: Process and function. Cell death Differ 23: 369-379, 2016.

5. Gao M, Monian P, Quadri N, Ramasamy R and Jiang X: Glutaminolysis and transferrin regulate ferroptosis. Mol Cell 59: 298-308, 2015.

6. Friedmann Angeli JP, Schneider M, Proneth B, Tyurina YY, Tyurin VA, Hammond VJ, Herbach N, Aichler M, Walch A, Eggenhofer E, et al: Inactivation of the ferroptosis regulator Gpx4 triggers acute renal failure in mice. Nat Cell Biol 16: 1180-1191, 2014.

7. Skouta R, Dixon SJ, Wang J, Dunn DE, Orman M, Shimada K, Rosenberg PA, Lo DC, Weinberg JM, Linkermann A and Stockwell BR: Ferrostatins inhibit oxidative lipid damage and cell death in diverse disease models. J Am Chem Soc 136: 4551-4556, 2014.

8. Linkermann A, Skouta R, Himmerkus N, Mulay SR, Dewitz C, De Zen F, Prokai A, Zuchtriegel G, Krombach F, Welz PS, et al: Synchronized renal tubular cell death involves ferroptosis. Proc Natl Acad Sci USA 111: 16836-16841, 2014.

9. Lorincz T, Jemnitz K, Kardon T, Mandl J and Szarka A: Ferroptosis is involved in acetaminophen induced cell death. Pathol Oncol Res 21: 1115-1121, 2015.

10. Uyeturk U, Terzi EH, Gucuk A, Kemahli E, Ozturk H and Tosun M: Prevention of torsion-induced testicular injury by Rhodiola rosea. Urology 82: 254.e1-6, 2013.

11. Chen SR and Liu YX: Regulation of spermatogonial stem cell self-renewal and spermatocyte meiosis by Sertoli cell signaling. Reproduction 149: R159-R167, 2015.

12. Cheng CY and Mruk DD: The biology of spermatogenesis: The past, present and future. Philos Trans R Soc Lond B Biol Sci 365: 1459-1463, 2010.

13. Griswold MD: The central role of Sertoli cells in spermatogenesis. Semin Cell Dev Biol 9: 411-416, 1998.

14. Mruk DD and Cheng CY: Sertoli-Sertoli and Sertoli-germ cell interactions and their significance in germ cell movement in the seminiferous epithelium during spermatogenesis. Endocr Rev 25: 747-806, 2004.

15. Tanwar PS, Kaneko-Tarui T, Zhang L, Rani P, Taketo MM and Teixeira J: Constitutive WNT/beta-catenin signaling in murine Sertoli cells disrupts their differentiation and ability to support spermatogenesis. Biol Reprod 82: 422-432, 2010.

16. Dokmeci D, Kanter M, Inan M, Aydogdu N, Basaran UN, Yalcin $\mathrm{O}$ and Turan FN: Protective effects of ibuprofen on testicular torsion/detorsion-induced ischemia/reperfusion injury in rats. Arch Toxicol 81: 655-663, 2007.

17. Moon C, Kim JS, Jang H, Lee HJ, Kim SH, Kang SS, Bae CS, Kim JC, Kim S, Lee Y and Shin T: Activation of Akt/protein kinase $\mathrm{B}$ and extracellular signal-regulated kinase in rats with acute experimental testicular torsion. J Vet Med Sci 70: 337-341, 2008.

18. Kanter M: Protective effects of Ginkgo biloba (EGb 761) on testicular torsion/detorsion-induced ischemia-reperfusion injury in rats. Exp Mol Pathol 91: 708-713, 2011.

19. Kim HJ, Lee JW, Hwang BR, Lee YA, Kim JI, Cho YJ, Jhun HJ and Han JS: Protective effect of pterostilbene on testicular ischemia/reperfusion injury in rats. J Pediatr Surg 51: 1192-1196, 2016.

20. Conrad $M$ and Sato $H$ : The oxidative stress-inducible cystine/glutamate antiporter, system x (c) (-): Cystine supplier and beyond. Amino Acids 42: 231-246, 2012.

21. Garg JP and Vucic D: Targeting cell death pathways for therapeutic intervention in kidney diseases. Semin Nephrol 36: 153-161, 2016.

22. Yang WS and Stockwell BR: Ferroptosis: Death by Lipid Peroxidation. Trends Cell Biol 26: 165-176, 2016.

23. Dixon SJ, Lemberg KM, Lamprecht MR, Skouta R, Zaitsev EM, Gleason CE, Patel DN, Bauer AJ, Cantley AM, Yang WS, et al: Ferroptosis: An iron-dependent form of nonapoptotic cell death. Cell 149: 1060-1072, 2012.

24. Hofmans S, Vanden Berghe T, Devisscher L, Hassannia B, Lyssens S, Joossens J, Van Der Veken P, Vandenabeele P and Augustyns K: Novel ferroptosis inhibitors with improved potency and ADME properties. J Med Chem 59: 2041-2053, 2016. 
25. Cao JY and Dixon SJ: Mechanisms of ferroptosis. Cell Mol Life Sci 73: 2195-2209, 2016.

26. Galluzzi L, Bravo-San Pedro JM, Kepp O and Kroemer G: Regulated cell death and adaptive stress responses. Cell Mol Life Sci 73: 2405-2410, 2016.

27. Li W, Wu ZQ, Zhao J, Guo SJ, Li Z, Feng X, Ma L, Zhang JS, Liu XP and Zhang YQ: Transient protection from heat-stress induced apoptotic stimulation by metastasis-associated protein 1 in pachytene spermatocytes. PLoS One 6: e26013, 2011.

28. Zhang S, Zeng Y, Qu J, Luo Y, Wang X and Li W: Endogenous EGF maintains Sertoli germ cell anchoring junction integrity and is required for early recovery from acute testicular ischemia/reperfusion injury. Reproduction 145: 177-189, 2013.

29. Erol B, Bozlu M, Hanci V, Tokgoz H, Bektas S and Mungan G: Coenzyme Q10 treatment reduces lipid peroxidation, inducible and endothelial nitric oxide synthases, and germ cell-specific apoptosis in a rat model of testicular ischemia/reperfusion injury. Fertil Steril 93: 280-282, 2010

30. Hotchkiss RS, Strasser A, McDunn JE and Swanson PE: Cell death. N Engl J Med 361: 1570-1583, 2009.

31. Linkermann A: Nonapoptotic cell death in acute kidney injury and transplantation. Kidney Int 89: 46-57, 2016.

32. Carlson BA, Tobe R, Yefremova E, Tsuji PA, Hoffmann VJ, Schweizer U, Gladyshev VN, Hatfield DL and Conrad M: Glutathione peroxidase 4 and vitamin E cooperatively prevent hepatocellular degeneration. Redox Biol 9: 22-31, 2016.

33. Kagan VE, Mao G, Qu F, Angeli JP, Doll S, Croix CS, Dar HH Liu B, Tyurin VA, Ritov VB, et al: Oxidized arachidonic and adrenic PEs navigate cells to ferroptosis. Nat Chem Biol 13: 81-90, 2017.

34. Li L, Yu Z, Miao G, Hui-juan W and Fu-lu G: Iron overload injures Sertoli cells of mouse. Basic Clin Med 36: 321-326, 2016.

35. Bogdan AR, Miyazawa M, Hashimoto K and Tsuji Y: Regulators of Iron Homeostasis: New players in metabolism, cell death, and disease. Trends Biochem Sci 41: 274-286, 2016.

36. Chen Y, Zhang S, Wang X, Guo W, Wang L, Zhang D, Yuan L, Zhang Z, Xu Y and Liu S: Disordered signaling governing ferroportin transcription favors breast cancer growth. Cell Signal 27: $168-176,2015$

37. Doll S, Proneth B, Tyurina YY, Panzilius E, Kobayashi S, Ingold I, Irmler M, Beckers J, Aichler M, Walch A, et al: ACSL4 dictates ferroptosis sensitivity by shaping cellular lipid composition. Nat Chem Biol 13: 91-98, 2017.

38. Yang WS, Kim KJ, Gaschler MM, Patel M, Shchepinov MS and Stockwell BR: Peroxidation of polyunsaturated fatty acids by lipoxygenases drives ferroptosis. Proc Natl Acad Sci USA 113 E4966-E4975, 2016

39. Dächert J, Schoeneberger H, Rohde K and Fulda S: RSL3 and Erastin differentially regulate redox signaling to promote Smac mimetic-induced cell death. Oncotarget 7: 63779-63792, 2016.

40. Conrad M and Friedmann Angeli JP: Glutathione peroxidase $4(\mathrm{Gpx} 4)$ and ferroptosis: What's so special about it? Mol Cell Oncol 2: e995047, 2015.

41. Yang WS, SriRamaratnam R, Welsch ME, Shimada K, Skouta R, Viswanathan VS, Cheah JH, Clemons PA, Shamji AF, Clish CB, et al: Regulation of ferroptotic cancer cell death by GPX4. Cell 156: 317-331, 2014.

42. Schneider M, Förster H, Boersma A, Seiler A, Wehnes H, Sinowatz F, Neumüller C, Deutsch MJ, Walch A, Hrabe de Angelis $\mathrm{M}$, et al: Mitochondrial glutathione peroxidase 4 disruption causes male infertility. FASEB J 23: 3233-3242, 2009.

43. Minutoli L, Antonuccio P, Polito F, Bitto A, Fiumara T, Squadrito F, Nicotina PA, Arena S, Marini H, Romeo C and Altavilla D: Involvement of mitogen-activated protein kinases (MAPKs) during testicular ischemia-reperfusion injury in nuclear factor-kappaB knock-out mice. Life Sci 81: 413-422, 2007.

44. Antonuccio P, Minutoli L, Romeo C, Nicòtina PA, Bitto A, Arena S, Altavilla D, Zuccarello B, Polito F and Squadrito F: Lipid peroxidation activates mitogen-activated protein kinases in testicular ischemia-reperfusion injury. J Urol 176: 1666-1672, 2006.

45. Yagmurdur H, Ayyildiz A, Karaguzel E, Ogus E, Surer H, Caydere M, Nuhoglu B and Germiyanoglu C: The preventive effects of thiopental and propofol on testicular ischemia-reperfusion injury. Acta Anaesthesiol Scand 50: 1238-1243, 2006.

46. Lee JW, Kim JI, Lee YA, Lee DH, Song CS, Cho YJ and Han JS Inhaled hydrogen gas therapy for prevention of testicular ischemia/reperfusion injury in rats. J Pediatr Surg 47: 736-742, 2012.
47. Al-Maghrebi M, Kehinde EO and Anim JT: Long term testicular ischemia-reperfusion injury-induced apoptosis: Involvement of survivin down-regulation. Biochem Biophys Res Commun 395: 342-347, 2010

48. Ergur BU, Kiray M, Pekcetin C, Bagriyanik HA and Erbil G: Protective effect of erythropoietin pretreatment in testicular ischemia-reperfusion injury in rats. J Pediatr Surg 43: 722-728, 2008.

49. Hong S, Kwon J, Kim DW, Lee HJ, Lee D and Mar W: Mulberrofuran $G$ protects ischemic injury-induced cell death via inhibition of NOX4-mediated ROS generation and ER stress. Phytother Res 31: 321-329, 2017.

50. Xu Q, Deng F, Xing Z, WuZ, Cen B, Xu S, Zhao Z, NepomucenoR, Bhuiyan MI, Sun D, et al: Long non-coding RNA C2dat1 regulates CaMKIIdelta expression to promote neuronal survival through the NF-kappaB signaling pathway following cerebral ischemia. Cell Death Dis 7: e2173, 2016.

51. Park H, Seol GH, Ryu S and Choi IY: Neuroprotective effects of (-)-linalool against oxygen-glucose deprivation-induced neuronal injury. Arch Pharm Res 39: 555-564, 2016.

52. Zhang YT, Li FM, Guo YZ, Jiang LR, Ma J, Ke Y and Qian ZM: (Z)-ligustilide increases ferroportin1 expression and ferritin content in ischemic SH-SY5Y cells. Eur J Pharmacol 792: 48-53, 2016.

53. Martin-Sanchez D, Ruiz-Andres O, Poveda J, Carrasco S, Cannata-Ortiz P, Sanchez-Niño MD, Ruiz Ortega M, Egido J, Linkermann A, Ortiz A and Sanz AB: Ferroptosis, but Not Necroptosis, is important in nephrotoxic folic acid-induced AKI. J Am Soc Nephrol 28: 218-229, 2017.

54. Turner RM: Moving to the beat: A review of mammalian sperm motility regulation. Reprod Fertil Dev 18: 25-38, 2006.

55. Namazi H: Decreasing the expression of LFA-1 and ICAM-1 as the major mechanism for the protective effect of hyperbaric oxygen on ischemia-reperfusion injury. Microsurgery 28: 300 , 2008.

56. Yao C, Li G, Qian Y, Cai M, Yin H, Xiao L, Tang W, Guo F and Shi B: Protection of pentoxifylline against testis injury induced by intermittent hypobaric hypoxia. Oxid Med Cell Longev 2016: $3406802,2016$.

57. Dokucu AI, Ozturk H, Ozturk H, Tuncer MC and Yilmaz F: The effects of molsidomine on hypoxia inducible factor alpha and Sonic hedgehog in testicular ischemia/reperfusion injury in rats. Int Urol Nephrol 41: 101-108, 2009.

58. Yu Y, Xie Y, Cao L, Yang L, Yang M, Lotze MT, Zeh HJ, Kang R and Tang D: The ferroptosis inducer erastin enhances sensitivity of acute myeloid leukemia cells to chemotherapeutic agents. Mol Cell Oncol 2: e1054549, 2015.

59. Shimada K, Skouta R, Kaplan A, Yang WS, Hayano M, Dixon SJ, Brown LM, Valenzuela CA, Wolpaw AJ and Stockwell BR: Global survey of cell death mechanisms reveals metabolic regulation of ferroptosis. Nat Chem Biol 12: 497-503, 2016.

60. Barber AA: Lipid peroxidation in rat tissue homogenates: Interaction of iron and ascorbic acid as the normal catalytic mechanism. Lipids 1: 146-151, 1966

61. El-Seweidy MM, Hashem RM, Abo-El-matty DM and Mohamed RH: Frequent inadequate supply of micronutrients in fast food induces oxidative stress and inflammation in testicular tissues of weanling rats. J Pharm Pharmacol 60: 1237-1242, 2008.

62. Sundarraj K, Manickam V, Raghunath A, Periyasamy M, Viswanathan MP and Perumal E: Repeated exposure to iron oxide nanoparticles causes testicular toxicity in mice. Environ Toxicol 32: 594-608, 2017.

63. Doreswamy K and Muralidhara: Genotoxic consequences associated with oxidative damage in testis of mice subjected to iron intoxication. Toxicology 206: 169-178, 2005.

64. Leichtmann-Bardoogo Y, Cohen LA, Weiss A, Marohn B, Schubert S, Meinhardt A and Meyron-Holtz EG: Compartmentalization and regulation of iron metabolism proteins protect male germ cells from iron overload. Am J Physiol Endocrinol Metab 302: E1519-1530, 2012.

65. Wauben-Penris PJ, Veldscholte J, van der Ende A and van der Donk HA: The release of iron by Sertoli cells in culture. Biol Reprod 38: 1105-1113, 1988.

66. Sylvester SR and Griswold MD: The testicular iron shuttle: A 'nurse' function of the Sertoli cells. J Androl 15: 381-385, 1994. 